\title{
Article
}

\section{Stakeholders' understanding and perceptions of bio-banding in junior-elite football training}

Reeves, Matthew, Enright, Kevin, Dowling, Jack and Roberts, Simon Available at http://clok.uclan.ac.uk/25214/

Reeves, Matthew ORCID: 0000-0002-3903-2910, Enright, Kevin, Dowling, Jack and Roberts, Simon (2018) Stakeholders' understanding and perceptions of bio-banding in junior-elite football training. Soccer \& Society, 19 (8). pp. 1166 1182. ISSN 1466-0970

It is advisable to refer to the publisher's version if you intend to cite from the work. http://dx.doi.org/10.1080/14660970.2018.1432384

For more information about UCLan's research in this area go to http://www.uclan.ac.uk/researchgroups/ and search for <name of research Group>.

For information about Research generally at UCLan please go to http://www.uclan.ac.uk/research/

All outputs in CLoK are protected by Intellectual Property Rights law, including Copyright law. Copyright, IPR and Moral Rights for the works on this site are retained by the individual authors and/or other copyright owners. Terms and conditions for use of this material are defined in the policies page.

\section{CLoK}

Central Lancashire online Knowledge www.clok.uclan.ac.uk

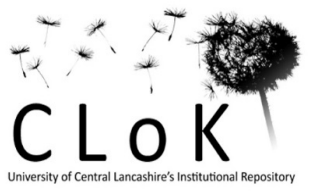


Stakeholder's understanding and perceptions of bio-banding in juniorelite football training

Matthew J. Reeves,,${ }^{1,2}$ Kevin J. Enright, ${ }^{1}$ Jack Dowling, ${ }^{3}$ Simon J. Roberts ${ }^{1}$

${ }^{1}$ Sport Coaching Research Group, Liverpool John Moores University, IM Marsh

Campus, Barkhill Road, Liverpool, L17 6BD.

${ }^{2}$ Research In Sport, Liverpool, UK.

${ }^{3}$ Everton Football Club Academy, Finch Farm Training Complex, Halewood, Liverpool, L26 3UE.

Matthew J. Reeves

+44 (0)1512315325

m.j.reeves@ljmu.ac.uk 


\section{Stakeholder's understanding and perceptions of bio-banding in junior- elite football training}

The purpose of this study was to investigate the understanding and perceptions of professional football academy staff, youth players and parents/carers in the use of 'bio-banding' during a seven week, pre-season training period. Data included a series of one-to-one semi-structured interviews and semi-structured focus groups with the three participant groups. Data were collected at three distinct times: 1) pre-bio-banded training; 2) during-bio-banded training; and 3) post-bio-banded training. Data were analysed qualitatively using a constant comparative approach. Results suggested that there are six key themes associated with biobanding pre-season training: 1) interpretation of bio-banding; 2) perceived disadvantages; 3 ) perceived advantages; 4) changes to coaching planning and practice; 5) educating stakeholders; and 6) logistical issues. This study concludes by proposing applied practitioners consider the findings as a framework to guide operationalising bio-banding in their environment.

Keywords: bio-banding, talent development, relative age effect, psychological development, sociological development, education 


\section{Introduction}

Annually age grouping children, for reasons of convenience and simplicity, is one typically employed by professional football academies in the United Kingdom (UK) and across Europe. ${ }^{1}$ Given the biological and maturational differences observed between children of similar ages, the grouping of children using chronological age can be problematic. ' 'Bio-banding' is considered an alternative method, which is where children are grouped or 'banded' according to their skeletal maturity rather than their chronological age. ${ }^{3}$

The pretext behind bio-banding is to reduce the impact of relative age effects (RAEs) that are reported to exist in professional football. ${ }^{4}$ The variation in birth dates amongst children in relation to age related cut-off points is commonly referred to as the 'relative age effect', and the subsequent implications are referred to as RAEs. ${ }^{5}$ RAEs occur as a direct consequence of placing children into chronological age groups for sporting competition. For example, in the UK the cut-off dates for participation in association football runs from September 1st - August 31st. This means that a player born in the month of September can be up to 12 months older than players in the same team (or the opposition team) born in August of the following year.

The prevalence of RAEs in competitive sport is documented in a meta-analytical review of 38 RAE studies, where significant uneven birth date distributions were reported ${ }^{6}$ in a number of sports including: baseball, ${ }^{7}$ ice hockey, ${ }^{8}$ football, ${ }^{9}$ both codes of rugby, ${ }^{10}$ and handball. ${ }^{11}$

Interestingly, however, RAEs are not as pronounced in female sports ${ }^{12}$ or where physicality is not required. ${ }^{13}$ For example, RAEs are not widely reported in non-contact sports, for example, golf. ${ }^{14}$ Presumably the absence of physical attributes (i.e. size, strength, and speed) permits relatively younger performers the opportunity to develop 
and improve their sporting skills without the issue of being compared with physically older peers. ${ }^{15}$

Despite the widespread reporting of RAEs in $\operatorname{sport}^{16}$ there is evidence that team selection and the identification of talented individuals favours those individuals who demonstrate greater physical maturity in relation to their chronological age at the selection stage. ${ }^{17}$ This has led to some claims that older, physically mature individuals, identified as talented have access to higher standards of coaching, and increased levels of competition than those individuals who are developmentally and biologically less mature. ${ }^{18}$ For instance, studies have repeatedly demonstrated that the composition of a male professional football squad contains an unequal distribution of players born closer to the cut-off point for selection. ${ }^{19}$

With the onset of puberty, which for boys usually occurs between 11-14 years of age and 10-12 years of age for girls,,$^{20}$ it is plausible that professional football may have overlooked potentially gifted younger players, as they were de-selected at the identification phase, due to talent scouts mistakenly observing physical maturity rather than technical/tactical aptitude. This supposition is supported by a cross-sectional epidemiological study, where age related data was adjusted to offset the age of participants and somatic maturity, but RAEs were still prevalent. ${ }^{21}$

Despite the volume of research dedicated to examining RAEs in varying contexts, there has been a shortage of hypothesis driven studies conducted to eradicate RAEs in youth sport. One recent exception is a study where selection bias in youth football was reduced by ensuring shirt numbers worn by young players were ordered according to their age. ${ }^{22}$ Although this study did not claim to reduce RAEs per se, it did provide evidence that with existing prior knowledge of RAEs, this discriminatory practice can be reduced. 
This is an important point, as previous research has suggested that sport coaches and sporting administrators responsible for the talent identification process have limited knowledge and understanding of RAEs. ${ }^{23}$ In contrast to previous RAE methodologies, the study of Roberts and Fairclough ${ }^{24}$ included a qualitative component to their UK based rugby union study, and via a series of in-depth interviews revealed the limited knowledge coaches involved in the talent identification process had of RAEs. There is also some evidence of pragmatic solutions to help eradicate or minimise RAEs, one such example is the relative age fair (RAF) system. ${ }^{25}$ In the RAF cycle system, the players are grouped via contiguous birth quarters, and thus the players are chosen from a full calendar year.

The potential for bio-banding as a mechanism to help minimise and eradicate RAEs in junior elite-football is an exciting new development, but it has yet to be fully established. However, as the use of bio-banding is now being explored further by the Premier League, ${ }^{26}$ though it must be noted, only in competition. Therefore, the focus of this work is to integrate new research with implementation, and as such, this study is one component of a larger multidisciplinary scale project conducted within a category one professional football academy. More specifically, this includes an examination of the talent identification and development philosophies and processes within the club and consideration of the individual learning objectives coaches provide for individual players. The purpose, therefore, of this particular study is to examine key stakeholder understanding and perceptions of the use of bio-banding during training within a juniorelite football environment. 


\section{Methodology}

\section{Participants \& Setting}

Three key stakeholder groups (players $n=66$; staff $n=8$; and parents/guardians $\mathrm{n}=80$ ) from an English Premier League academy participated in this study. Players were aged between 9.2 years of age and 14.2 years of age ( \pm 1.5 years). Parents were aged between 31 and 53 years of age ( \pm 6.1 years). Both players and parents were recruited to the study through purposive sampling approaches (Palys, 2008). ${ }^{27}$ Fourteen days prior to the data collection phase, an invitation to participate in the study was sent to coaches, and parents/children via direct email communication. This message included the participant information sheet which described the aims and objectives of the study, a consent form, and an invitation to be involved in a focus group interview one week later to discuss their involvement in the study.

Staff participants were aged between 27 years of age and 48 years of age $( \pm 7.76$ years) and were a combination of staff from the coaching $(n=4)$ and recruitment $(n=4)$ departments. Staff were recruited through a purposive sampling approach, though only included coaches who would be involved in coaching a bio-banded group, meaning $80 \%$ of eligible coaches were included in this study. Recruitment staff were recruited through convenience sampling with $57 \%$ of full time recruitment staff were included in this study. The study was approved by an internal ethics board at a University within the United Kingdom and conformed to the code of ethics of the World Medical Association.

\section{Classification of Skeletal Maturity}

Players were categorised according to their skeletal maturity using methods previously described. ${ }^{28}$ In brief, players' and parents' heights were measured using a stadiometer (SECA, Birmingham, United Kingdom) to the nearest $0.01 \mathrm{~m}$ with the 
participant standing feet together, toes touching a standardised mark on the floor. The head was placed in the Frankfort plane. Each participant was instructed to take and hold a deep breath whilst the head plate of the stadiometer was placed down on the vertex. Measurement was taken prior to the subject exhaling. Each child's body mass was also measured to the nearest $0.1 \mathrm{~kg}$ using calibrated weighing scales (SECA, Birmingham, United Kingdom). The estimated predicted adult height of the children was calculated using the following equation described by Khamis \& Roche ${ }^{29}:(22.7+$ $1.37 \mathrm{x}$ height +2 years). Previous studies using this method and participants have demonstrated acceptable agreement. ${ }^{30}$ Following this the participant's predicted percentage of adult height was calculated and used to group the children according to their 'skeletal maturity'. At present, there is no recommended way to group participants based on their skeletal maturity without adopting invasive measures such as hand-wrist X-rays. Such approaches include the Greulich-Pyle method, ${ }^{31}$ the Tanner-Whitehouse method, ${ }^{32}$ and the Fels method. ${ }^{33}$ As such, groups were designed so that the population could be separated into five equal groups, based on estimated final adult stature (group $1, \leq 77.9 \%$; group $2,78-81.9 \%$; group 3, 82-85.9\%; group 4, 86-89.9\%; and group 5 $90 \%+$ ) (see Table 1). Group 1 was included in the study, though only comprised of under 10 players.

Table 1. Breakdown of bio-banded groups by chronological age

\begin{tabular}{lllll}
\hline $\begin{array}{l}\mathbf{7 7 7 . 9 \%} \text { final } \\
\text { adult stature }\end{array}$ & $\begin{array}{c}\mathbf{7 8 - 8 1 . 9 \%} \\
\text { final adult } \\
\text { stature }\end{array}$ & $\begin{array}{c}\mathbf{8 2 - 8 5 . 9 \%} \\
\text { final adult } \\
\text { stature }\end{array}$ & $\begin{array}{c}\mathbf{8 6 - 8 9 . 9 \%} \\
\text { final adult } \\
\text { stature }\end{array}$ & $\begin{array}{c}\mathbf{9 0 \%} \text { + final } \\
\text { adult stature }\end{array}$ \\
$\mathrm{U} 10=12$ & $\mathrm{U} 10=4$ & $\mathrm{U} 11=1$ & $\mathrm{U} 12=1$ & $\mathrm{U} 13=1$ \\
& $\mathrm{U} 11=12$ & $\mathrm{U} 12=8$ & $\mathrm{U} 13=13$ & $\mathrm{U} 14=13$ \\
& $\mathrm{U} 12=4$ & $\mathrm{U} 13=4$ & $\mathrm{U} 14=1$ & \\
TOTAL $=\mathbf{1 2}$ & TOTAL $=\mathbf{2 0}$ & TOTAL $=\mathbf{1 3}$ & TOTAL $=\mathbf{1 2}$ & TOTAL $=\mathbf{1 4}$ \\
\hline
\end{tabular}




\section{Interviews \& Focus Groups Procedure}

One-to-one interviews ( $\mathrm{n}=88)$ were conducted with academy staff $(\mathrm{n}=22)$ and players $(n=66)$. Focus groups $(n=80)$ were conducted with parents. Interviews and focus groups were conducted at three times: prior to the start of pre-season training, during pre-season training, and after pre-season training had occurred. All interviews and focus groups were semi-structured in design with a flexible questioning schedule that ensured specific topics were covered, ${ }^{34}$ but allowed respondents the opportunity to explore topics not included within the questioning schedule. The interview schedules for each phase of qualitative data collection (i.e. pre-, during-, and post-bio-banded preseason training) were similarly shaped to ensure consistency of the evaluative and exploratory nature of the inquiry. The questioning schedules focussed on two broad areas: 1) understanding of bio-banding; and 2) potential impact upon player development. Whilst these two broad thematic areas were constant for all participants, the phrasing was adapted to reflect the role of the different participant groups (e.g. parents we're asked what they perceived the impact would be on their son).

The players were interviewed pre- $(n=24)$, during- $(n=12)$, and post- $(n=30)$ biobanded pre-season training. Interviews ranged in length from 5 minutes to 16 minutes (9 minutes' average). Staff were also interviewed pre- $(n=7)$, during- $(n=8)$, and post$(n=7)$ bio-banded pre-season training. Interviews ranged in length from 17 minutes to 55 minutes (37-minute average). Finally, parents participated in focus groups pre- (12 focus groups; $n=30$ ), during- (10 focus groups; $n=23$ ), and post- (11 focus groups; $\mathrm{n}=27$ ) bio-banded pre-season training. Focus groups ranged in length from 14 minutes to 52 minutes (39 minutes' average). All interviews were digitally recorded and transcribed verbatim for data analysis purposes. 


\section{Data Analysis}

All formal interviews and focus groups were digitally recorded and transcribed verbatim. Once all data were available they were imported in to QSR NVivo 10 and analysed using a constant comparative method, that is, comparing any newly collected data with previous data collected in earlier studies (Rubin \& Rubin, 1995). ${ }^{35}$ Data collection and data analysis occurred concurrently: Data were subjected to open and axial coding to determine the number of concepts and categorisations. Themes were considered significant enough for reporting when there was a minimum agreement of $50 \%$ amongst participants. ${ }^{36}$

\section{Open Coding}

Open coding aims to identify concepts and associated dimensions and properties. ${ }^{37}$ Thus, data were initially broken down and examined; similarities and differences were identified and a numbers of concepts developed. As the open coding process continued, comparative analysis took place, whereby concepts with similar characteristics were grouped together, where there were no similarities between data units and existing concepts, new ones were generated. Concepts that considered similar issues were assembled as categories (i.e. higher order level) and sub-categories. Descriptive labels, which outlined the essential characteristics of each category or subcategory, were applied to assist in the data characterisation process. ${ }^{38}$

\section{Axial Coding}

An axial coding process was undertaken to reassemble data that had been broken down during the open coding process. ${ }^{39}$ This process allowed for more accurate descriptions and representation of the perceptions of bio-banding being used for training purposes in a junior-elite environment. Data were conceptually developed through 
asking questions related to understanding of bio-banding (i.e. its purpose, potential benefits, etc.). It was important at all times that data were not forced into the existing conceptual framework, generated through the axial coding process, but that constant comparison continued to explore the similarities and differences within the data. ${ }^{41}$

\section{Findings \& Discussion}

The study was concerned with two main issues: understanding and perceptions of bio-banding. In terms of examining the issue of understanding, this was divorced from the rest of the analysis by being a pre-determined 'theme'. Therefore, whilst we have included interpretation of bio-banding as a theme, it must be considered more in terms of evaluating stakeholders' understanding, than being their perception of biobanding.

Analysis of the data identified six themes related to the perceptions of stakeholders in relation to the use of bio-banding in a junior-elite training environment: (1) interpretation of bio-banding; (2) perceived disadvantages; (3) perceived advantages; (4) changes to coaching planning and practice; (5) educating stakeholders; and (6) logistical issues. These core themes are presented below in Table 1.

Table 2. Overview of the themes, descriptions, and raw data quotations.

\begin{tabular}{lll} 
Theme & Description & Example of raw data quotations \\
\hline $\begin{array}{l}\text { Interpretation of bio- } \\
\text { banding }\end{array}$ & $\begin{array}{l}\text { Demonstration of } \\
\text { knowledge and } \\
\text { understanding of what } \\
\text { bio-banding is and } \\
\text { why it might be a } \\
\text { useful development } \\
\text { tool. }\end{array}$ & $\begin{array}{l}\text { "...where the kids are in their maturation, so } \\
\text { the bone development, how they are in the } \\
\text { body...so if an 8-year-old could have the body } \\
\text { of a 10-year-old, erm, he is obviously more } \\
\text { physically mature and obviously more } \\
\text { developed than other boys in his group } \\
\text { whereas someone in that group could have, } \\
\text { you know, the body or the physique of a 7- } \\
\text { year-old." }\end{array}$
\end{tabular}


Perceived

disadvantages

Perceived

advantages

Changes to coaching planning \& practice

Educating stakeholders
Negative elements of involvement in biobanding

Positive elements of involvement in biobanding

Changes to coaching practice and/or planning as a result of training sessions being bio-banded.

Any discussion of stakeholders for whom education of bio-banding would be beneficial.
"So, bio-banding, basically putting boys in groups of physical relevance rather than chronological age."

"Basically just splitting it into height differences."

"I think it will have an effect on some of them who are getting, who are seen as getting moved down."

“... it is a sensitive area and it could have an impact on player retention or the lads' performance throughout pre-season."

"I think it might knock his confidence a bit."

"I think probably most impact for the boys themselves is going to be the psychological impact."

"The positives obviously any less developed boys, you know, they are going to be judged against lads who are the same maturity as them..."

"seeing a boy in a different environment and making you think 'bloody hell, he's actually alright, he's actually very technically competent' or 'he's very, you know, very switched on, his spatial awareness is outstanding."

"It has actually made me think a bit differently and simplify things and, erm, try and tweak. I ended up having these things in and then no, I'm just going to do this and then work within differently with the players."

"No. It wouldn't change how I, erm, think about my sessions."

“...so, planning and designing a session, erm, to be fair I'm not sure. I'm not totally sure how it is going to affect it. I don't know if it would."

“[Player's name]'s, dad phoned me, erm, he didn't have enough information, you know, didn't know why, didn't understand the reasons for it, 'is he lesser than the players in his group, is this why he's playing down?"'

"I think we've got to be clear with the communication from the start, why we're doing it, what the benefits are, what research tells us, what are the disadvantages of it but why the positives outweigh the negatives, you 
know and just answer any questions that the parents have."

"I think everyone's getting used to it, staff, players, parents so it is something we've never done."

Logistical issues Any suggestion of factors associated with the organisational and delivery factors associated with "...the communication on it has been a bit messy..."

"I just think it is completely the wrong time to do this because new coaches are getting new groups and don't know the boys."

"now we've switched groups and so it has been a bit messy in terms of getting your numbers right, from my point of view."

\section{Interpretation of bio-banding}

The most common theme to emerge from the data related to participants' interpretation of the term bio-banding. Across the data collection phases (i.e. pre-, during-, and post-bio-banded pre-season training) there was some gradual improvement in the level of understanding of bio-banding from all participant groups, though some misunderstanding was still evident within each group, despite relevant information being sent to stakeholders by the head of sport science $\&$ medicine approximately two weeks prior to the start of pre-season. Whilst the term 'bio-banding' is not new in football discourse,${ }^{41}$ investigations concerning its application in football are still very much in their infancy. However, it was anticipated that their knowledge and understanding would have been higher than the data suggested, particularly given its adoption by the premier league. For example, one senior member of coaching staff indicated this concern:

“...my only concern would be, it is just everybody understanding why we're doing it. That's my only concern, does everybody fully understand why we're doing it and it is so important that everyone does, parents, player, coach, because if they don't fully understand then it could just be seen as, 'what are we doing this for? This is a waste of time, he shouldn't be with this group, he should be in there' and 
then that affects the dynamics in the group. So that would be my only concern because it is something fairly, it is new and making sure that everybody knows and understands why we're doing it would be my only concern." (Staff 5, pre)

Whilst there were staff who were able to correctly explain the notion of biobanding and its application to junior-elite football, these were limited:

"I understand it in terms of it is measuring the percentage of growth compared to what the potential height is going to be and then pairing them up with the boys that have grown at the same rates and so it is more evenly matched." (Staff 6, pre)

There appeared to be a lack of clarity regarding the impact that bio-banding might have in a training context. There were instances of participants being able to explain what bio-banding is and also offering perceptions of how it might affect the player development pathway.

“...but, ultimately if it can add a small part to the development of a boy and help their journey towards the First Team then I don't see why we shouldn't be open minded enough to have a look at it and form our own opinions." (Staff 7, during)

Some staff respondents $(n=3)$ were able to accurately articulate what biobanding is and how it may be beneficial whilst others $(n=5)$ were not. This indicates that there is an element of professional learning that have occurred for some staff, but not others. Notions of unmediated learning seemed apparent, ${ }^{42}$ as staff sought new information, but on their own terms, and only when they considered it important. In this instance, there appeared to be a miss-match between seeking new information and understanding that information. Here, participants regularly confused bio-banding as being concerned with height adjusted groupings (i.e. players of the same height being grouped together), as opposed to being concerned with skeletal maturity. 
"I think it is matching boys more on their heights and weights as opposed to their actual birthday...erm and putting them in the same groups as boys both physically and mentally as well, that have a similar aptitude as opposed to 'you're in this age group and that's where you fit in." (Staff 1, pre)

At the beginning of the study the parents demonstrated little understanding of the term. However, over the course of the training period the parents were more adept at demonstrating their knowledge and understanding of bio-banding.

\footnotetext{
"I wondered myself if it was more based around matching them height wise, you know, in the age groups and then giving everyone pretty much even." (Parent 8 , pre)

"I understand it in terms of it is measuring the percentage of growth compared to what the potential height is going to be and then pairing them up with the boys that have grown at the same rates...but I've had to find that out myself...the stuff we were sent at the start wasn't right for me." (Parent 49, post)
}

This change in knowledge and understanding was not impacted by the academy as, intentionally, there was no education programme provided, indicating that parents sought their own additional information; which may have been brought about by their involvement in this study. However, this newly found knowledge and the ability to communicate their understanding of bio-banding suggests that parents feel the need to be able to better understand particular issues in order to effectively support their child. Similar findings have been presented elsewhere. ${ }^{43}$ Indeed, previous studies have referred to parents as exhibiting a necessity to support their children "to be and to become" ${ }^{" 44}$ suggesting that their primal need to provide support and security for their offspring requires them to develop appropriate knowledge and understanding of concepts in order to do so. In the demanding world of football parents may be willing to do whatever it takes to support their child to succeed, regardless of the potential stress it may cause ${ }^{45}$ or perceived requirement to fulfil societal expectations. ${ }^{46}$ 
Players demonstrated the least accurate understanding of bio-banding across data collection periods. Despite a consistent lack of understanding from players, they were aware of the key elements and attributes that helped determine their bio-banded group (i.e. age, current weight, current height, parental height) indicating, as with other participant groups, that they did have a level of understanding.

"I think it is about, like, erm, how you are as, not like your ability, like how tall you are, what your weight is and stuff like that and like being the same with other people, with your, not the same ability but with the same, like, standing." (Player 47 , post)

Considering the varied interpretations of bio-banding as a concept, and its impact upon all stakeholders, it was interesting to note that there was very little resistance to the initiative taking place. There are a number of possible reasons for this: 1) staff may operate in a culture of trust, openness and confidence that such activities, especially when driven by other departments (i.e. sport science and medicine) are wellresearched and offer appropriate development opportunities; ${ }^{47}$ 2) issues of power may have manifest, whereby coaches felt unable to speak-out against a decision that had been made. Indeed, it is well established that notions of power are embedded in the culture of professional football. ${ }^{48}$

Whilst not resistant to the implementation of bio-banding, staff highlighted that they were disappointed not to have been consulted on the programme or the impact on coaching and pedagogic practice. Indeed, it has been suggested that there is a need for consultation and cooperation between perspectives of coaches and sport scientists, particularly within performance sport environments. ${ }^{49}$

\footnotetext{
"No, we've had no discussion around it. I've had an e-mail 'this is what we're doing, bio-banding, this is what we're doing' which to be fair is a little bit disappointing because it's a conversation that we've been having in the office amongst some of the
} 
coaches for a little while now yet when the actual decision is made there has been no, nobody has been seeking information from the coaches' perspectives even though we're the ones living it day in, day out, there has been no opinion from us, it has almost been 'this is starting, here's an e-mail, that's it, get on with it' whereas we're the ones living it, we're the ones who are hoping to be educated from it. We want to know how it is going to look, what are we expecting?" (Staff 7, pre)

There appeared to be an issue of how coaches acquire and utilise sport science knowledge in their practice. Previous studies have demonstrated that coaches undervalue the benefits of scientific knowledge,${ }^{50}$ whilst others suggest that rapport amongst coaches and scientists, as opposed to actual scientific knowledge, is more important to the adoption of research and scientific principles within coaching practice ${ }^{51}$ However, the topical nature of bio-banding within junior-elite football at the time of this study might suggest that coaches might have a better grasp of the issue.

\section{Perceived disadvantages}

There was a range of perceived disadvantages reported by respondent groups, though these reduced as pre-season progressed. The main perceived disadvantage for staff was related to the retention of players during the bio-banding period, especially those players and parents who, through their misunderstanding of bio-banding, may interpret that players had been 'moved down' an age group.

\footnotetext{
"I think we need to be as transparent as possible with it because it is a sensitive area and it could have an impact on player retention or the lads' performance throughout pre-season going into the new season. It might not, but why take that risk?" (Staff 3, pre)
}

Recruitment staff were the most conscious of the potential detrimental effects to retention of players. However, players and parents reported that there was no likelihood of retention being an issue. Instead, parents reported that they trusted the academy staff 
to do what is right for their son's development, and that bio-banding would not be adopted if staff didn't believe there was any value in doing so.

"I don't think something like this would make us leave...the people in that building are the experts here, not me, not him, not him...I drive, he's a bricky, and he's a sparks, what do we really know about anything like this? We just have to trust that them lot know what they're doing." (Parent 4, pre)

"You've always got to be looking at ways to improve and if they think that they can improve the groups, you know, and get more kids through.” (Parent 7, pre)

Feelings of apprehension were raised by some players, brought about by the potential for social isolation when moving between different groups and not being with friends or, at least, other players with whom they are familiar. It is well established that children's participation in sport has a large social element, ${ }^{52}$ and it is possible that is could be compromised by adopting a bio-banded approach. ${ }^{53}$ There might be value, however, in proposing a hybrid model whereby players switch between bio-banded, ability-based, and psycho-banded groups. ${ }^{54}$

“...maybe if I was put in a different group and I wouldn't know all the people as much and stuff, so, I wouldn't speak to them as much maybe or it depends what group I went in, maybe like not speak to them much. It might affect like in the game if I'm not speaking to them as much." (Player 27, during)

Parents (a mixture of mothers and fathers) focussed on issues they perceived to disadvantage their son. For example, a number of parents commented on the speed and intensity of training when their son was banded with a majority of younger players. They commented on how they feared this might affect their son's development and how coaches might perceive his ability. This concern remained throughout the pre-season period. Staff respondents, however, noted the same issue (i.e. speed of sessions), but saw the potential benefit for the player in that instance. 
“...the speed is a lot slower, it is a different game to what he's used to, erm, it will be interesting to see how they adjust ..." (Parent 34, during)

\footnotetext{
"That said the boys who have moved down have developed certain aspects of their game and have been allowed to play the game at a speed that is comfortable to them as opposed to playing at 100mph constantly to keep up with the big boys, erm, and that obviously has a by-product of they get more returns in the four corners as well. You know, a boy who is not worried about just keeping up with the older lads, the more physically developed boys. It allowed them to take almost a deep breath and play the game how they really see it through their own eyes." (Staff 2, post)
}

Here, parents' heightened sense of responsibility in junior-elite football may be a key factor. ${ }^{55}$ It has previously been suggested that parenting expertise in youth sport rests upon six key postulates, ${ }^{56}$ the most pertinent in this instance being that parents 'manage organisational and developmental demands associated with sports participation'. It is further posited that parents are inundated with challenges related to organisational factors and processes that can affect many facets of their life, including demands to their child's development in sport and that these challenges require a variety of "intrapersonal, interpersonal and organizational skills and strategies". 57 The issue in question may be perceived as a club-based organisational stressor, which appears to become more prominent as children become more specialised in their sports participation. $^{58}$

\section{Perceived advantages}

Staff respondents, including those who had been unable to clearly articulate the purpose of bio-banding, were able to offer ideas about what they would expect players to develop during the bio-banded training period. Indeed, the perceived advantages of bio-banding training could be split into three distinct categories: psychological, sociological, and technical/tactical. The most commonly cited amongst participants 
were psychological. This is an important issue for consideration as bio-banding, whilst taking an aspect of biological development into consideration, does not account for psychological development, and the two do not necessarily occur simultaneously. ${ }^{59}$

"Firstly, and foremost I think, for me, confidence and self-esteem are massive things for a footballer at any age. Players need to feel comfortable in the environment that they are working in, erm, and have that freedom to express themselves. Something that I've seen is that the boys that are slightly behind physically, play with more of an anxiety, erm, and sometimes our decision making gets clouded... I see boys who I'm working with who have just as good game understanding but they don't have the physical capability, erm, or the confidence to express it as consistently." (Staff 5 , pre)

There have been a number of applied sport psychology studies within juniorelite football that have sought to examine the development of mental toughness. ${ }^{60}$ These studies have reported the inadequacies of how coaches develop psychological skills in comparison to other domains of performance, especially technical and tactical. However, in this study, respondents perceived that psycho-social attributes had been developed, including confidence, leadership, and responsibility.

"I went down and it was kind of easier in the football but it helped me become a leader, cos I'm quite quiet in the group and I could become a bit more of a leader." (Player 55, post)

“I mean it's not been my favourite but like you are playing football aren't you, the good thing about it. But, yeah, it is, it gave me an experience to say if I'm playing with younger people it is like, 'oh, these are younger, I'm much better than them', well you can't do that because you've got to show them, like, the responsibility of being an older age person." (Player 50, post)

Older players (U13-U14), predominantly training with younger players, demonstrated improved attitude, competence, and efficacy. This is consistent with previous findings around personal and social responsibility (PSR) development where 
adolescence has been highlighted as a critical time point for its development. ${ }^{61}$ It is well established that coaches have an important role to play in developing PSR through the unique position they hold, ${ }^{62}$ particularly in junior-elite environments, to affect such outcomes. ${ }^{63}$ Players also highlighted that they perceived technical developments had occurred, with data suggesting that these technical developments were brought about by positive changes in confidence.

\footnotetext{
"I had one of the parents phone me, the young lad, the under 11, parent saying 'god, them older lads were brilliant weren't they today with the young ones, even on the coach our [player name] said 'the older lad called him down the bus, come and sit next to me' talking about the game to him 'you know, you need to start thinking about this'. I did say to them they had the freedom to do what they thought was best." (Staff, 2 during)
}

"I'm like small in my group like playing against some of the bigger lads, it was hard, you know, cos they're bigger and more developed and stuff. But when I was playing with people like my own size and that, you feel like you can do more things." (Player 54, post)

This demonstrates a level of self-awareness that expert coaches have been reported to look for as an influencing factor in player development. ${ }^{64}$ Furthermore, it highlights the potential of bio-banding for bringing about and manifesting such changes.

\section{Changes to coaching planning and practice}

Staff respondents did not perceive that groups being bio-banded would affect the planning and practice delivery. Given the unknown remit of delivering bio-banded training sessions, it may be understandable that coaches felt that their planning or practice would be affected. However, it may also be plausible to expect coaches to change their planning and practice based on the different age groups involved within their particular group. There are a number of features that may have brought about 
change, such as consideration of the social dynamics within the group, potential changes to the focus and desired outcomes of the sessions, and many more.

"I...I don't see how it would affect me...I'd still work with them individually and I'd still build it up to work with the group." (Staff 5, pre)

"No. No. It wouldn't change how I, erm, think about my sessions... I always challenge them with my sessions." (Staff 1, pre)

If we accept that there was no consideration of changes to planning or delivery, then it might be suggested that coaching in this context can be reduced to generic approaches, processes, and rules that are too simplistic to be useful ${ }^{65}$ and reinforces a notion of coaches not needing to consider their planning and practice when working with specific groups.

Whilst the majority of staff who responded about changes to planning and practice did not or could not qualify why there would not be any change, some suggested that their planning was always player-centred and individualised and so would continue to be so. However, some staff referred to the perceived difficulty in openly and honestly questioning practice and approaches to player development. This, perhaps, represents the hierarchical, top-down leadership and management approach commonly found within football. ${ }^{66}$ This manifest as a belief amongst staff that there would be no resistance involved in trying something new, but the level of buy-in and commitment would vary dependant on the coach (i.e. traditionalist vs progressive coaches).

"I think it has caused lots of discussion, I think there'll be lots of people going 'pffff that bio-banding's shit, a waste of time, what have they got from it?' I think people with the closed minds will say 'we'll just close it off straight away', 'it will be shit before we're doing it, shit while we're doing it and shit after it' and that will 
be some people. Other people will really see and I think if there are enough people see something out of it, it will be another way to try and change." (Staff 5, pre)

\begin{abstract}
"Erm, probably not because there's, there's ways that have worked in the past, you know and players have come through the system without bio-banding so that's an obvious reason why people have seen the player's journey, 'why didn't player X need it? He made it', you know, so, I think there may be resistance but that's natural...actually, I'm not sure if, you know, it's resistance, more just commitment and buy-in to what we're trying." (Staff 4, pre)
\end{abstract}

Whilst there was no reported change to coaching practice, players perceived that they had developed socially. Therefore, bio-banded groups appear to create environments whereby players engage with different sets of peers and coaches and are required to operate within different technical constraints which foster opportunities for the social development of players. The unique cultures of professional football clubs are well-documented, ${ }^{67}$ but the effectiveness of these in developing social skills is less well known despite evidence that general social skills are fundamental to the success of junior-elite footballers. ${ }^{68}$

\title{
Educating stakeholders
}

Both staff and parents highlighted the importance of educating stakeholders in activities such as bio-banding. Indeed, staff consistently emphasised this message throughout the data collection periods. Staff regularly stressed how important parental buy-in was to activities being successful, particularly when they were being driven by other departments (i.e. sport science and medicine), as these departments tend not to have direct relationships with parents. Parents have been found to experience feelings of increased responsibility toward their sons within a junior-elite football academy environment. ${ }^{69}$ Many staff referred to parents as the most important people to 'have on side' and it could be suggested that anything outside of the norm for parents represents a 
challenge to their enhanced parental identity, and further heightens their already increased parental responsibility. ${ }^{70}$

\begin{abstract}
"Now, the people that may affect that when they get in the car is the parents. So, for me education with the parents is more important than the boys being aware of what they're doing because they just want to play. The parent's messages when they get in the car need to reinforce ours and not contradict. So, I want an education to the parents, that's vital to me because they are the main stakeholders in their boy and they make the big decisions at the end of the day and if we upset some of our players, you know, we don't want that to happen and there's no reason why we should as long as they understand why we're doing this over this period and I'm not sure that they do at the moment." (Staff 5, during)
\end{abstract}

"Uncertainty as to why we're [staff] doing it and involving us in the process, let us have some buy in, don't just send us an e-mail with a link to an article at the bottom saying 'this is what we're doing'. That's cold and that's, that wasn't very helpful to be honest." (Staff 7, post)

Neither staff nor parents suggested that players required further education on such issues. Indeed, players often suggested that they were not too concerned with whom they were playing with or against, so long as they were actually playing football, further supporting the idea of that stakeholder group not requiring further education on this issue.

“...it doesn't, like, matter who you're with... you are playing football aren't you, the good thing about it." (Player 54, post).

One of the most enduring issues related to the perceptions of participants that players had been moved up or down. This was consistent across all participant groups. The language adopted, even when participants understood and could articulate what bio-banding is, was one of players being moved 'up' or 'down'. This highlights a need for an agreed taxonomy to aide education of the process of bio-banding and remove 
potential barriers to understanding. Issues of language have been raised in the coaching science literature, whereby the dissemination of scientific concepts are poorly understood as the use of more appropriate lay language rarely occurs. ${ }^{71}$

"Yeah. There was like two or three that moved down." (Player 47, post)

"...how they feel and what sort of spin they get put on it if they do get moved down. I think if they get moved up they'll feel good about themselves." (Parent 4, pre)

Coaches' knowledge, understanding, and application of sports science in their practice remains a frustrating problem. ${ }^{72}$ However, this perennial problem seems to extend beyond coaches and staff, and now includes parents.

\section{Logistical issues}

Logistical issues were raised chiefly by staff respondents. Indeed, staff frequently highlighted a number of logistical and organisational issues that bio-banded groups during pre-season had caused. The most common issue related to the timing of the trial. There were a number of negative thoughts toward bio-banding during preseason, though some positive perceptions also came through.

"I just feel that at the moment it could have been done later on in the season and I think we could have possibly got more data and used it more effectively..." (Coach 3 , pre)

"I was just thinking about there is, it is good that you do it at this stage of the year, er, because they've just had a break and when you have a break their bodies change because it gives them the time to relax and stretch and grow. So, it is probably the best time of year to do it, thinking about it in that way and it is just that we probably need to clear up everything that's in the way of it, let's go with biobanding and work out where other stuff fits in." (Coach 1, during) 
Pre-season was seen by many coaches as an opportunity for getting to know their group and begin to develop relationships. Indeed, the importance of developing coach-athlete relationships is well established.$^{73}$ Despite its importance, many clubs operating in a junior-elite environment continue to operate a year-by-year change of coach as players move to their next age group. Therefore, this period for the development of coach-athlete relationships is considered crucial by coaches, and the introduction of a period which inhibits such development may be detrimental to this process. Adopting bio-banding for training purposes meant that some players were coached by different coaches during pre-season. This change to the coach-athlete dynamic could be an inhibiting factor for player development, as previous studies have highlighted that as knowledge of each other (i.e. coach and athlete) increases, so does the capacity of the coach to enhance their athlete's development. ${ }^{74}$ Whilst not a direct logistical issue (e.g. training time, travel), it was an issue brought about by the logistics of organising such activity at an already congested period.

Alongside the development of relationships there were also issues around player and staff attendance. In the UK, pre-season in junior-elite football falls during the school summer holiday period (i.e. late July-August). Therefore, players and their families often use this time for family holidays and trips. Similarly, many clubs are engaged in tours with respective age group teams. This created situations whereby some bio-banded groups were disrupted by virtue of the number of players present. Interview data suggested that this was not uncommon, however, and usually occurred during pre-season even when groups are chronologically arranged.

\footnotetext{
"It is for the right reasons it is just, it has just been a bit messy for whatever reason, stage of the season, tours, whatever you want to say, it has just been a bit difficult to run with it, to get a constant flow of what is going on, whether holidays or whatever else...pre-seasons like that though anyway." (Coach 1, during)
} 
A final logistical issue pertained to players who were attending the academy on trial. Whilst they would usually be with their chronological age group, this was not possible. Therefore, an additional complexity was encountered: the sport science department, in collaboration with the recruitment department, had to attempt to gather the necessary data points to be able to determine the player's correct bio-banded group.

\footnotetext{
"We have got a lot of trialists coming in over the next few weeks... and, you know, I've had to work to get the stuff needed to make sure these boys are going in the right groups. They're always coming in at this time, but this is something else I've had to do that I wasn't expecting to."
}

Whilst the bio-banding activity added an additional level of work that was unexpected and unplanned for, this would not be uncommon, regardless of the timing of bio-banding. However, it does raise the issue of workload and responsibility for this type of activity and highlights the required interdisciplinary working at junior-elite level.

\section{Conclusion}

The data presented above provide the first known examination of stakeholders' perceptions of the use of bio-banding within a junior-elite football training environment. The only other study ${ }^{75}$ that has considered the use of bio-banding in junior-elite football only focussed upon players' perceptions and data were collected during a competitive tournament.

This study highlighted six key themes, that emerged over a five-week pre-season training period. The emergent themes should be considered carefully in any junior-elite performance environment prior to the operationalisation of bio-banded training. Whilst wide-ranging, the topics covered in this study provides a useful framework for other clubs to adopt and issues for them to consider before adopting similar practices. It also 
lends itself to guiding further studies in this area, for example, examining specific psychological and sociological traits and skills that bio-banding may impact. Whilst all of the findings lend themselves to applied practice within junior-elite football environments, the issues bio-banding attempt to overcome (i.e. those associated with RAE) appear to pertain more readily to developing attributes within the psychological and sociological domains of performance. By better understanding the potential use of bio-banding in junior-elite football, we are able to consider how the talent development pathway can be shaped to help overcome issues of RAE. This investigation offers a first step in evaluating how a relatively new approach to training and competition in junior-elite football may better support late maturing players in their development, whilst also offering a different challenge to early maturing players in their development, too.

\section{Recommendations for future studies}

The breadth of areas highlighted in this study, and the relative infancy of biobanding within junior-elite football means that there are significant areas for future inquiry. Firstly, we would suggest that there is a need to understand the session intensity differences between chronological and bio-banded groups. By better understanding the session intensities, more effective season and session programming can occur. Secondly, we suggest a need to examine how psychological and social skills can and are developed during bio-banded training in junior-elite football. Finally, we suggest the need to understand the most appropriate differential between bands. For example, in this study, 3.9\% final adult height were adopted for logistical reasons, however, this may not have been the most appropriate banding to bring about the most benefit for players and further work is needed on this issue. 


\section{Acknowledgements}

The authors would like to thank all participants for their involvement in the study. We would also like to thank the reviewers for their comments that have helped to better shape this paper. 


\section{Notes}

1. Carling et al., Do anthropometric and fitness characteristics.

2. Till et al., Considering maturation status.

3. Tucker, Raferty and Verhagen, Injury risk.

4. Helsen, Winckel and Williams, The relative age effect.

5. Musch and Grondin, Unequal competition; Roberts and Stott, A new factor in UK students'.

6. see Cobley et al., Annual age-grouping.

7. Thompson, Barnsley and Stebelsky, "Born to play ball".

8. Boucher and Mutimer, The relative age phenomenon.

9. Helsen, Winckel and Williams, The relative age effect.

10. Abernethy and Farrow, Contextual factors.

11. Schorer et al., Influences of competition level.

12. Lidor et al., Relative age effect.

13. Delorme and Rauspaud, The relative age.

14. Côté et al., When "where" is more important.

15. Lidor et al., Relative age effect.

16. Cobley et al., Annual age-grouping.

17. Wattie, Cobley and Baker, Towards a unified understanding.

18. Ibid.

19. Vaeyens, Philippaerts and Malina, The relative age effect; Helsen, Winckel and Williams, The relative age effect.

20. Malina et al., Biological maturation.

21. Roberts et al., The influence of relative age; Bailey and Collins, The standard model.

22. Mann and van Ginneken, Age-ordered shirt numbering.

23. Roberts and Fairclough, The influence of relative age.

24. Ibid.

25. Hurley, Lior and Tracze, "A proposal to reduce".

26. Cumming, Premier League Growth Study; Cumming et al., Premier league academy soccer.

27. Palys, "Purposive sampling," 697-698.

28. Khamis and Roche, Predicting adult stature.

29. Ibid.

30. Malina et al., Maturity status.

31. Greulich and Pyle, Radiographic atlas.

32. Tanner et al., Assessment of skeletal maturity; Tanner \& Whitehouse, A new system.

33. Roche, Chumlea and Thissen, Assessing the skeletal maturity.

34. Patton, "Qualitative research and evaluation".

35. Rubin and Rubin, "Qualitative interviewing".

36. Reeves and Roberts, Perceptions of performance analysis.

37. Strauss and Corbin, "Basics of qualitative research".

38. Maykut and Morehouse, "Beginning qualitative research".

39. Strauss and Corbin, "Basics of qualitative research".

40. Ibid. 
41. see Bilton, Developing players.

42. Werthner and Trudel, A new theoretical perspective.

43. Wiersma and Fifer, "The schedule has been tough"; Clarke and Harwood, Parenting experiences; Clarke, Harwood and Cushion, A phenomenological interpretation.

44. van Manen, "Researching lived experience", 59.

45. Harwood, Drew and Knight, Parental stressors.

46. Clarke and Harwood, Parenting experiences.

47. see Bailey and Collins, The standard model.

48. Potrac and Jones, Power, conflict, and cooperation; Cushion and Jones, 2006, Power, discourse, and symbolic violence.

49. Williams and Kendall, Perceptions of elite coaches.

50. Ibid.

51. Reade, Rogers and Hall, Knowledge transfer.

52. Bailey, Cope and Pearce, Why do children.

53. Allendar, Cowburn and Foster, Understanding participation in sport.

54. Tucker, Referty and Verhagen, Injury risk.

55. Clarke and Harwood, Parenting experiences.

56. Harwood and Knight, Parenting in youth sport, 30.

57. Ibid.

58. Harwood and Knight, Stress in youth sport.

59. Vaeyens et al., Talent identification and development.

60. For example, Crust and Azadi, Mental toughness; Cook et al., 'What it takes'.

61. Santos et al., Personal and social responsibility.

62. Camiré, Trudel and Bernard, A case study.

63. Flett et al., Tough love.

64. Mills et al., Identifying factors.

65. Cushion, Modelling the complexity.

66. Relvas et al., Organizational structures.

67. Nesti and Sulley, "Youth development in football".

68. Larsen, Alferman and Christensen, Psychosocial skills.

69. Clarke and Harwood, Parenting experiences.

70. Ibid.

71. see Williams and Kendall, Perceptions of elite coaches.

72. Ibid.

73. Vella, Oades and Crowe, The relationship between coach leadership.

74. Mageau and Vallerand, The coach-athlete relationship.

75. Cumming et al., Premier league academy soccer. 


\section{References}

Abernethy, A. B., and D. Farrow. "Contextual Factors Influencing the Development of Expertise in Australian Athletes." In ISSP 11th World Congress of Sport Psychology: Promoting Health and Performance for Life, edited by Tony Morris, Peter C. Terry, Sandy Gordon, Stephanie Hanrahan, Lydia Ievleva, Gregory Kolt, and Patsy Tremayne. Sydney, Australia: International Society of Sport Psychology, 2005.

Bailey, Richard P., and Dave Collins. "The Standard Model of Talent Development and Its Discontents.” Kinesiology Review 2, no. 4 (2013): 248-59.

Bailey, Richard, Edward J Cope, and Gemma Pearce. "Why Do Children Take Part In, and Remain Involved in Sport? A Literature Review and Discussion of Implications for Sports Coaches." International Journal of Coaching Science 7, no. 1 (2013): 56-75.

Bilton, John. "Developing Players for the Modern Game Football Academies: The Start - the Leeds United Experience.” Coaching 2, no. 3 (1999): 33-36.

Boucher, Jacques L., and Brian T. P. Mutimer. "The Relative Age Phenomenon in Sport: A Replication and Extension with Ice-Hockey Players." Research Quarterly for Exercise and Sport 65, no. 4 (1994): 377-81. doi:10.1080/02701367.1994.10607644.

Camiré, Martin, Pierre Trudel, and Dany Bernard. "A Case Study of a High School Sport Program Designed to Teach Athletes Life Skills and Values.” The Sport Psychologist 27, no. 2 (2013): 188-200. doi:10.1123/tsp.27.2.188.

Carling, Chris, Franck Le Gall, Tom Reilly, and A. Mark Williams. "Do Anthropometric and Fitness Characteristics Vary according to Birth Date Distribution in Elite Youth Academy Soccer Players?" Scandinavian Journal of Medicine \& Science in Sports 19, no. 1 (2009): 3-9. doi:10.1111/j.16000838.2008.00867.x.

Clarke, Nicola J., and Chris G. Harwood. "Parenting Experiences in Elite Youth Football: A Phenomenological Study." Psychology of Sport and Exercise 15, no. 5 (2014): 528-37. doi:10.1016/j.psychsport.2014.05.004.

Clarke, Nicola J., Chris G. Harwood, and Chris J. Cushion. "A Phenomenological Interpretation of the Parent-Child Relationship in Elite Youth Football." Sport, 
Exercise, and Performance Psychology 5, no. 2 (2016): 125-43.

doi:10.1037/spy0000052.

Cobley, Stephen, Joseph Baker, Nick Wattie, and Jim McKenna. "Annual Age-

Grouping and Athlete Development." Sports Medicine 39, no. 3 (2009): 235-56. doi:10.2165/00007256-200939030-00005.

Cook, Clive, Lee Crust, Martin Littlewood, Mark Nesti, and Jacquelyn Allen-Collinson. “"What It Takes': Perceptions of Mental Toughness and Its Development in an English Premier League Soccer Academy." Qualitative Research in Sport, Exercise and Health 6, no. 3 (2014): 329-47. doi:10.1080/2159676X.2013.857708.

Côté, Jean, Dany J. Macdonald, Joseph Baker, and Bruce Abernethy. "When 'where' Is More Important than 'when': Birthplace and Birthdate Effects on the Achievement of Sporting Expertise.” Journal of Sports Sciences 24, no. 10 (2006): 1065-73. doi:10.1080/02640410500432490.

Crust, Lee, and Kayvon Azadi. “Mental Toughness and Athletes' Use of Psychological Strategies.” European Journal of Sport Science 10, no. 1 (2010): 43-51. doi:10.1080/17461390903049972.

Cumming, Sean. "Premier League Growth Study.” In SPRINZ Conference. Rosedale, Auckland, 2015. http://bit.ly/2jN1cpc.

Cumming, Sean P., Daniel J. Brown, Siobhan Mitchell, James Bunce, Dan Hunt, Chris Hedges, Gregory Crane, et al. 'Premier League Academy Soccer Players' Experiences of Competing in a Tournament Bio-Banded for Biological Maturation.” Journal of Sports Sciences iFirst (June 19, 2017). doi:10.1080/02640414.2017.1340656.

Cushion, Chris. "Modelling the Complexity of the Coaching Process." International Journal of Sports Science and Coaching 2, no. 4 (2007): 395-401. doi:10.1260/174795407783359650.

Cushion, Christopher, and Robyn L. Jones. "Power, Discourse, and Symbolic Violence in Professional Youth Soccer: The Case of Albion Football Club." Sociology of Sport Journal 23, no. 2 (2006): 142-61. doi:10.1123/ssj.23.2.142.

Delorme, Nicolas, and Michel Raspaud. "The Relative Age Effect in Young French Basketball Players: A Study on the Whole Population." Scandinavian Journal of Medicine \& Science in Sports 19, no. 2 (2009): 235-42. doi:10.1111/j.16000838.2008.00781.x. 
Flett, M. Ryan, Daniel Gould, Katherine R. Griffes, and Larry Lauer. "Tough Love for Underserved Youth: A Comparison of More and Less Effective Coaching." The Sport Psychologist 27, no. 4 (2013): 325-37. doi:10.1123/tsp.27.4.325.

Greulich, William Walter, and S. Idell Pyle. Radiographic Atlas of Skeletal Development of the Hand and Wrist. Stanford, CA: Stanford University Press, 1950.

Harwood, Chris G., and Camilla J. Knight. "Parenting in Youth Sport: A Position Paper on Parenting Expertise.” Psychology of Sport and Exercise 16 (2015): 24-35. doi:10.1016/j.psychsport.2014.03.001.

Harwood, Chris, Ashleigh Drew, and Camilla J. Knight. "Parental Stressors in Professional Youth Football Academies: A Qualitative Investigation of Specialising Stage Parents." Qualitative Research in Sport and Exercise 2, no. 1 (March 2010): 39-55. doi:10.1080/19398440903510152.

Harwood, Chris, and Camilla Knight. "Stress in Youth Sport: A Developmental Investigation of Tennis Parents." Psychology of Sport and Exercise 10, no. 4 (2009): 447-56. doi:10.1016/j.psychsport.2009.01.005.

Helsen, Werner F., Jan Van Winckel, and A. Mark Williams. "The Relative Age Effect in Youth Soccer across Europe.” Journal of Sports Sciences 23, no. 6 (2005): 629-36. doi:10.1080/02640410400021310.

Hurley, William, Dan Lior, and Steven Tracze. "A Proposal to Reduce the Age Discrimination in Canadian Minor Hockey.” Canadian Public Policy 27, no. 1 (2001): 65-75. doi:10.2307/3552374.

Khamis, Harry J., and Alex F. Roche. "Predicting Adult Stature without Using Skeletal Age: The Khamis-Roche Method.” Pediatrics 94, no. 4 (1994): 504-7.

Lansley, Pete. "Bio-Banding Will Create Better Leaders and People," 2016. http://www.premierleague.com/en-gb/news/news/2015-\%0A16/sep/170915premier-league-bio-banding-helping-latedevelopers.html.

Larsen, Carsten, Dorothee Alfermann, and Mette Christensen. "Psychosocial Skills in a Youth Soccer Academy: A Holistic Ecological Perspective.” Sport Science Review 21, no. 3-4 (2012): 51-74. doi:10.2478/v10237-012-0010-х.

Lidor, Ronnie, Michal Arnon, Zohar Maayan, Tamar Gershon, and Jean Côté. "Relative Age Effect and Birthplace Effect in Division 1 Female Ballgame Players - the Relevance of Sport-Specific Factors.” International Journal of Sport and 
Exercise Psychology 12, no. 1 (2014): 19-33.

doi:10.1080/1612197X.2012.756232.

Mageau, Geneviève A, and Robert J Vallerand. "The Coach-athlete Relationship: A Motivational Model.” Journal of Sports Sciences 21, no. 11 (2003): 883-904. doi:10.1080/0264041031000140374.

Malina, Robert M, Alan D Rogol, Sean P Cumming, Manuel J Coelho E Silva, and Antonio J Figueiredo. "Biological Maturation of Youth Athletes: Assessment and Implications.” British Journal of Sports Medicine 49, no. 13 (2015): 85259. doi:10.1136/bjsports-2015-094623.

Malina, Robert M., Sean P. Cumming, Peter J. Morano, Mary Barron, and Susan J. Miller. "Maturity Status of Youth Football Players: A Noninvasive Estimate." Medicine and Science in Sports and Exercise 37, no. 6 (2005): 1044-52. doi:10.1249/01.mss.0000171622.45134.cb.

Mann, David L., and Pleun J. M. A. van Ginneken. "Age-Ordered Shirt Numbering Reduces the Selection Bias Associated with the Relative Age Effect." Journal of Sports Sciences iFirst (2016). doi:10.1080/02640414.2016.1189588.

Maykut, Pamela, and Richard Morehouse. Beginning Qualitative Research: A Philosophical and Practical Guide. Lewes, UK: Falmer Press, 1994. Mills, Andrew, Joanne Butt, Ian Maynard, and Chris Harwood. "Identifying Factors Perceived to Influence the Development of Elite Youth Football Academy Players.” Journal of Sports Sciences 30, no. 15 (2012): 1593-1604. doi:10.1080/02640414.2012.710753.

Musch, Jochen, and Simon Grondin. "Unequal Competition as an Impediment to Personal Development: A Review of the Relative Age Effect in Sport." Developmental Review 21, no. 2 (2001): 147-67. doi:10.1006/drev.2000.0516.

Nesti, Mark, and Chris Sulley. Youth Development in Football: Lesson from the World's Best Academies. Oxon: Routledge, 2015.

Palys, Ted. "Purposive Sampling." In The Sage Encyclopedia of Qualitative Research Methods: Volume 2, edited by Lisa M. Given, 697-98. London: Sage, 2008.

Patton, Michael Q. Qualitative Research and Evaluation Methods. 3rd ed. London: Sage, 2002.

Potrac, Paul, and Robyn Jones. "Power, Conflict, and Cooperation: Toward a Micropolitics of Coaching." Quest 61, no. 2 (2009): 223-36. doi:10.1080/00336297.2009.10483612. 
Reade, Ian, Wendy Rodgers, and Nathan Hall. "Knowledge Transfer: How Do High Performance Coaches Access the Knowledge of Sport Scientists?” International Journal of Sports Science and Coaching 3, no. 3 (2008): 319-34. doi:10.1260/174795408786238470.

Reeves, M.J., and S.J. Roberts. "Perceptions of Performance Analysis in Elite Youth Football.” International Journal of Performance Analysis in Sport 13, no. 1 (2013): 200-211.

Relvas, Hugo, Martin Littlewood, Mark Nesti, David Gilbourne, and David Richardson. "Organizational Structures and Working Practices in Elite European Professional Football Clubs: Understanding the Relationship between Youth and Professional Domains.” European Sport Management Quarterly 10, no. 2 (2010): 165-87. doi:10.1080/16184740903559891.

Roberts, Simon J., Lynne M. Boddy, Stuart J. Fairclough, and Gareth Stratton. "The Influence of Relative Age Effects on the Cardiorespiratory Fitness Levels of Children Age 9 to 10 and 11 to 12 Years of Age." Pediatric Exercise Science 24, no. 1 (2012): 72-83. doi:10.1123/pes.24.1.72.

Roberts, Simon J., and Stuart J. Fairclough. "The Influence of Relative Age Effect in the Assessment of High School Students in Physical Education in the United Kingdom.” Journal of Teaching in Physical Education 31, no. 1 (2013): 56-70.

Roberts, Simon J., and Tim Stott. “A New Factor in UK Students' University Attainment: The Relative Age Effect Reversal?" Quality Assurance in Education 23, no. 3 (2015): 295-305. doi:10.1108/QAE-01-2013-0008.

Roche, A. F., W. C. Chumlea, and D. Thissen. Assessing the Skeletal Maturity of the Hand-Wrist: Fels Method. Springfield, IL: Charles C Thomas, 1988.

Rubin, Herbert J, and Irene S Rubin. Qualitative Interviewing: The Art of Hearing Data. London: Sage, 1995.

Santos, Fernando, Nuno Corte-Real, Leonor Regueiras, Cláudia Dias, and António Fonseca. "Personal and Social Responsibility Development: Exploring the Perceptions of Portuguese Youth Football Coaches within Competitive Youth Sport." Sports Coaching Review iFirst (2016). doi:10.1080/21640629.2016.1249643.

Schorer, J., S. Cobley, D. Büsch, H. Bräutigam, and J. Baker. "Influences of Competition Level, Gender, Player Nationality, Career Stage and Playing 
Position on Relative Age Effects." Scandinavian Journal of Medicine \& Science in Sports 19, no. 5 (2009): 720-30. doi:10.1111/j.1600-0838.2008.00838.x.

Strauss, Anselm, and Juliet M. Corbin. Basics of Qualitative Research: Techniques and Procedures for Developing Grounded Theory. 2nd ed. London: Sage, 1998.

Tanner, J.M., R. H. Whitehouse, N. Cameron, W. A. Marshall, M. J. R. Healy, and H. Goldstein. Assessment of Skeletal Maturity and Prediction of Adult Height (TW2 Method). New York, NY: Academic Press, 1975.

Tanner, James Mourilyan, and R. J. Whitehouse. A New System for Estimating Skeletal Maturity from the Hand and Wrist: With Standards Derived from a Study of 2,600 Healthy British Children. Paris: International Children's Centre, 1962.

Thompson, Angus H., Roger H. Barnsley, and George Stebelsky. “'Born to Play Ball” the Relative Age Effect and Major League Baseball.” Sociology of Sport Journal 8, no. 2 (1991): 146-51. doi:10.1123/ssj.8.2.146.

Till, Kevin, Steve Cobley, John O’ Hara, Carlton Cooke, and Chris Chapman.

"Considering Maturation Status and Relative Age in the Longitudinal Evaluation of Junior Rugby League Players." Scandinavian Journal of Medicine \& Science in Sports 24, no. 3 (June 2014): 569-76. doi:10.1111/sms.12033.

Tucker, Ross, Martin Raftery, and Evert Verhagen. "Injury Risk and a Tackle Ban in Youth Rugby Union: Reviewing the Evidence and Searching for Targeted, Effective Interventions. A Critical Review.” British Journal of Sports Medicine 50, no. 15 (2016): 921-25. doi:10.1136/bjsports-2016-096322.

Vaeyens, Roel, Matthieu Lenoir, A. Mark Williams, and Renaat M. Philippaerts. "Talent Identification and Development Programmes in Sport: Current Models and Future Directions." Sports Medicine 38, no. 9 (2008): 703-14.

Vaeyens, Roel, Renaat M. Philippaerts, and Robert M. Malina. "The Relative Age Effect in Soccer: A Match-Related Perspective.” Journal of Sports Sciences 23, no. 7 (2005): 747-56. doi:10.1080/02640410400022052.

Manen, Max van. Researching Lived Experience: Human Science for an Action Sensitive Pedagogy. New York, NY: State University of New York Press, 1990.

Vella, Stewart A., Lindsay G. Oades, and Trevor P. Crowe. "The Relationship between Coach Leadership, the Coach-athlete Relationship, Team Success, and the Positive Developmental Experiences of Adolescent Soccer Players.” Physical Education \& Sport Pedagogy 18, no. 5 (2013): 549-61. doi:10.1080/17408989.2012.726976. 
Wattie, Nick, Stephen Cobley, and Joseph Baker. "Towards a Unified Understanding of Relative Age Effects." Journal of Sports Sciences 26, no. 13 (2008): 1403-9. doi:10.1080/02640410802233034.

Werthner, Penny, and Pierre Trudel. “A New Theoretical Perspective for Understanding How Coaches Learn to Coach.” Sport Psychologist 20, no. 2 (2006): 198-212. Wiersma, Lenny D., and Angela M. Fifer. “"The Schedule Has Been Tough but We Think It's Worth It': The Joys, Challenges, and Recommendations of Youth Sport Parents." Journal of Leisure Research 40, no. 4 (2008): 505-30.

Williams, S. John, and Lawrence Kendall. "Perceptions of Elite Coaches and Sports Scientists of the Research Needs for Elite Coaching Practice.” Journal of Sports Sciences 25, no. 14 (2007): 1577-86. doi:10.1080/02640410701245550. 